\title{
Craniosacral Therapy and Suspected Compression Fracture
}

\author{
Sundardas Dharmadas Annamalay* \\ Natural Therapies Research Centre, Singapore
}

Submission: November 06, 2017; Published: November 14, 2017

*Corresponding author: Sundardas Dharmadas Annamalay, Natural Therapies Research Centre, Singapore 188035, Email: sundardasa@gmail.com

\begin{abstract}
Craniosacral therapy (CST) is a therapeutic technique that helps re-establish the proper flow of cerebral spinal fluid and normalizing the craniosacral rhythm (CSR) throughout the dural tube Craniosacral Therapy (CST) has become a useful manual approach for the management of acute and chronic musculoskeletal conditions in an ageing population. This reviews a case history of a client with suspected compression fracture. She was assessed with listening stations, tissue drag, pulse diagnosis, the MRI reports and surgeon's reports. Evaluations and findings suggested multiple visceral restrictions and other cranial lesions that were contributing to her symptoms. She was treated using a variant of the 10-step protocol commonly used by practitioners trained in the Upledger style of CST. There was a subsequent reduction of pain levels by about fifty percent over a one and half hour session.
\end{abstract}

Keywords: Craniosacral therapy; Craniosacral rhythm; Musculoskeletal; Ageing; Pain; Compression fracture; Cranial lesion

\section{Introduction}

Cerebral spinal fluid fills the dural tube, cushions our brain and spinal column, like a shock absorber, brings nourishment to our nerves, and transports waste material to be recycled rhythmically [1,2]. Craniosacral therapy (CST) $[3,4]$ is a therapeutic technique that helps re-establish the proper flow of cerebral spinal fluid and normalizing the craniosacral rhythm (CSR) $[1,2]$. When a restriction or blockage occurs in the dural tube, the flow of nourishment is impaired and can affect the optimal performance of nerves and the organs they innervate. CST attempts to resolve restrictions and provide optimal flow of nourishment throughout the dural tube $[3,4]$. The "Ten Step Protocol" $[3,4]$ begins with an evaluation of the craniosacral rhythm (CSR) [1,2] as observed through the musculoskeletal system. This evaluation is segmented via seven regions of the body to allow for comparative analysis to determine the type of restriction and its primary and secondary locations [3]. Often secondary restrictions must be released to clarify diagnosis of the primary dysfunction.

I saw 81 year old Chinese lady who is the mother in-law of one of my current patients who is a senior medical doctor, complaining of lower back pain. Her son-in law suspected she had a vertebral compression fracture of lower lumbar region and he did not want her to experience an extended hospital stay and take pain killers because of her multiple medical complications.
A. Symptoms: Lower back pain, neck and right arm, discomfort. She also experienced some incontinence as well as fatigue and difficulty in visual accommodation.

B. Medical History: Her medical history was very significant. She has a history of diverticulitis of the colon. She had multiple surgeries done. The most recent was a laparotomy for the closure of end ileostomy. Her abdomen had multiple scars.

When the surgeon had gone into her bowels during surgery he discovered the following:

a. Chronic granulation in the middle of the previous laparotomy scar.

b. Adhesions between small bowels to the scar, interloo and small bowel to bladder fundus.

c. Vesicotomy was performed as well due to adhesions between small bowel to bladder.

d. Rectal stump up to the level of sacral promontory

\section{Material and Methods}

\section{Tools used}

Assessing her with listening stations $[1,2,5]$ tissue drag, pulse diagnosis, the MRI reports and surgeon's reports. Treatment 
methods involved Craniosacral Therapy. Evaluation and Findings: Abdominal diaphragm restrictions due to surgeries and scarring, especially referencing the right hypochondrium at the level of the right kidney. Right mastoid involvement. Evaluation of the cranial vault identified right side bending restriction of the sphenobasilar synchondrosis [6-8]. The right sternocleiodomastoid, right anterior scalene muscles were all in a state of tension.

\section{Discussion}

As I was going through the first few sequences of the listening stations [3] I kept getting a strong response to visceral restrictions due to the surgeries and scar tissue. All the listening stations up to the anterior inferior costal region kept referencing the right hypochondrium at about the level of the right kidney. The anterior shoulders listening station suggested a lesion at the right mastoid.

So I returned to work at the level of the right hypochondrium. I started off with at the pelvic diaphragm. There were multiple adhesions, and involvement of the right psoas and right ilacus. After releases at been obtained at that level, I worked at the scarring that centered around the bladder fundus. The median and medial umbilical ligaments were injured as well. After releases were obtained, I moved to release the small intestinal restrictions. Despite the surgical interventions there were still adhesions between the small intestines and the bladder. It became more apparent there after that the right psoas was actually reacting to the ptosis of the right kidney. As the ptosis of the right kidney was released, the involvement of the right vagus and right phrenic nerve became more obvious. I went up to the respiratory diaphragm and continued releases. At the thoracic outlet the vagal and phrenic involvement was clearly defined as well as the right cervical plexus region. At this point I continued with the listening and resumed the 10 step protocol $[3,4]$. Evaluation of the cranial vault identified right side-bending restriction of the sphenobasilar synchondrosis. The right sternocleiodomastoid, right anterior scalene muscle were all in a state of tension.

\section{Conclusion}

Her response to the treatment was gratifying positive. She experienced a $50 \%$ reduction in symptoms. One month later, her son-law the doctor mentioned that she was doing the marketing and cooking very easily and comfortably. So over a one and half hour treatment, were symptoms were greatly improved. The cost of the treatment was $\$ 250$. Her son in-law told me that my intervention probably saved her about $\$ 3,000$ in medical fees and assessments and hospitalization and weeks of suffering. So CST is a useful tool cost-effective for pain management in an ageing population.

\section{References}

1. Ernest Retzlaff W, Richard Fred Becker, John Upledger E (1976) Craniosacral mechanism. Journal of the American Osteopathic Association p. 6.

2. Milicien Tettambd (1978) Recording of cranial rhythmic impulse. Journal of the American Osteopathic Association 78: 149.

3. John E Upledger, Jon D Vredevoogd (1982) Cranio Sacral therapy.

4. John E Upledger (1996) Somato emotional release and beyond.

5. Ernest Retzlaff W, John E Upledger, Fred L Mitchell, Thomas Biggerr (1977) Sutural collagenous bundles and their inneryation in saimic scureus. Anatomical Record p. 187.

6. Ernest W Retzlaff, John E Upledger, Fred L Mitchell, Thomas Biggerr (1978) Nerve fibers and endings in cranial sutures. Journal of the American Osteopathic Association p. 77.

7. Ernest W Retzlaff, John E Upledger, Ruth Walsh, Fred L Mitchell (1979) Aging of sutures in humans. Anatomical Record 193(3): 1.

8. Ernest W Retzlaff, Fred L Mitchell, John E Upledger, Jon D Vredevoogd, Ruth Walsh, et al. (1980) Light and scanning microscopy of neuroaxis in human cranial sutures and associated structures. Anatomical Record 196(3): A151-A200.

\section{Your next submission with Juniper Publishers will reach you the below assets}

- Quality Editorial service

- Swift Peer Review

- Reprints availability

- E-prints Service

- Manuscript Podcast for convenient understanding

- Global attainment for your research

- Manuscript accessibility in different formats

( Pdf, E-pub, Full Text, Audio)

- Unceasing customer service

Track the below URL for one-step submission https://juniperpublishers.com/online-submission.php 